\title{
Providing medical services at Olympics a huge task
}

$\mathrm{T}$ he London 2012 Olympic Games are winding to a close, but thousands of health professionals at the event remain busy treating any and every form of ailment. There are certain health problems one expects to see among elite athletes. Stress fractures. Muscle strains. Other musculoskeletal injuries resulting from repeatedly pushing the human body to its limit. But at massive gatherings of athletes such as the Olympic and Paralympic Games, medical professionals see so much more.

"You have to be prepared to treat anything and everything," says Dr. Jack Taunton, a professor of sports medicine at the University of British Columbia who served as the chief medical officer for the Vancouver 2010 Olympic and Paralympic Games.

About $10 \%$ of athletes at these competitions will suffer an injury, and approximately $7 \%$ will contract an illness, according to Dr. Robert McCormack, the medical director for the Canadian Olympic Committee at the 2012 Games in London, United Kingdom. "We have had everything from simple colds to hospital admissions for a pelvic fracture and closed head injury," McCormack writes in an email from London.

One challenge of providing medical care at mass sports gatherings is that people from different countries could potentially introduce a wide range of health risks. People from areas with high incidence rates of some transmissible diseases mingle with people from nations where those diseases are less common, for example. Medical workers must be prepared to treat a wide range of illnesses.

"We also have to remember that the Olympics is where the viruses of the world come to meet, and it is winter in the southern hemisphere," writes McCormack.

It can also be challenging to convince elite athletes to follow particular courses of treatment or therapy that interfere

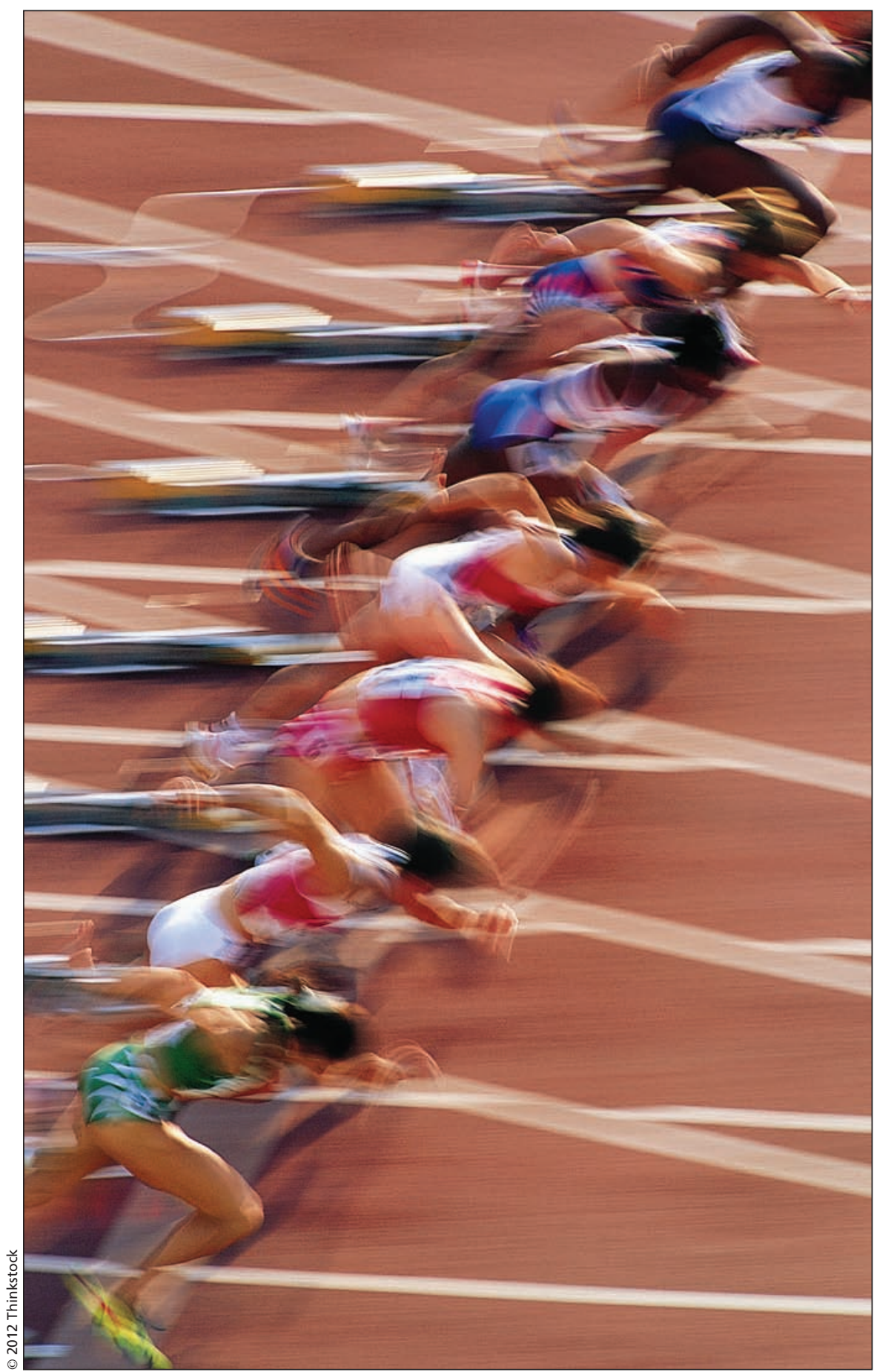

Olympic athletes may appear superhuman, but they suffer a host of injuries and illnesses.

with their training or, even worse, with their ability to compete in Olympic events. "The challenge is they want to compete even when it is not ideal from the medical perspective," writes McCormack. "We have to tread the line of protecting them and still respecting their rights to make a decision." 
Indeed, world class athletes suffering from injury or illness tend to ask the same questions: When can I train again? When can I compete again? Can something be done to speed up the healing process?

"You have to find alternative means of keeping them fit while the injury is healing," says Taunton. "They are always in a time squeeze."

Not only are health professionals tasked with helping athletes, they must also tend to volunteers, members of the media, coaches, dignitaries, support staff and spectators. At the London Olympics, there are an estimated 10500 athletes from 205 nations (another 4200 are expected at the Paralympic Games), 20000 accredited media members and a work force of about 200000 (including paid workers, volunteers and contractors). As for spectators, there were about 8 million tickets for sale (www.londontown.com /London/Olympic-Facts--Figures).

The medical staff and volunteers must be highly organized to provide care at many different locations. Over the 19 days of the London Olympics, 302 events were held at 32 different venues with a total capacity of 700000 . Most services, however, were offered at a primary location - a polyclinic in the Olympic Village that resembles a small hospital. It offered primary care, sports medicine, physiotherapy, optometry, ophthalmology, dental care, medical imaging and podiatry, among other services. There were also on-call specialists available in cardiology, dermatology, neurology, surgery, psychiatry, gastroenterology and other areas.

At the Vancouver Games, two major clinics were established, one in Vancouver and the other in Whistler, each measuring 10000 square feet. Preparations took four and a half years and an estimated 9000 people received medical care. "They had everything you could possibly think of having in terms of hospital outpatient services," says Taunton.

There were also two 54-foot trailers on site that contained operating rooms, trauma beds and blood supplies. "We had to be able to open your head, open your chest and open your belly," says Taunton.

Though severe injuries do sometimes occur, much of the work done by medical professionals at the Olympic and Paralympic Games is basic, primary care. At the Vancouver Games, a percentage of athletes, many of whom were too busy training to visit their dentists, received dental screening, uncovering numerous infections that could have led to chronic inflammation and other health problems.
The eye care stations also tend to be busy at the Games, especially if free glasses and contact lenses are up for grabs. The free medical care and supplies prove particularly attractive to athletes from countries with limited access to first-rate health care.

"Some third world countries do avail themselves of the care available. Especially the dental services are in great demand," writes McCormack. "However, I personally think it is reasonable to support these disadvantaged athletes when the Olympics benefits from their participation."

So, given the complexities and challenges of providing the wide range of health services required, why do so many medical professionals sacrifice their time and skills for the Olympic cause? "Almost all the Canadian medical staff at the Olympics works as volunteers. It is truly a love of sport that motivates them to contribute. Their medical practices at home are already as busy as they can cope with, so there is no financial benefit to spending a month at the Olympics," writes McCormack. "Having said that, there are great rewards in helping someone maximize their potential and succeed on the world stage." - Roger Collier, CMAJ

CMAJ 2012. DOI:10.1503/cmaj.109-4268 